\title{
ONCOCYTIC ADRENAL CORTICAL ADENOMA PRESENTING AS CUSHING'S SYNDROME: AN EXCEPTIONAL CLINICAL ENTITY
}

\begin{abstract}
Maria Molina-Vega, Araceli Muñoz-Garach, Silvia Maraver-Selfa, Ana Gomez-Perez, Isabel Cornejo-Pareja, Cristina DiazPerdigones, Isabel Mancha-Doblas, Francisco Tinahones-Madueño

Department of Endocrinology and Nutrition. Virgen de la Victoria Hospital, Malaga, Spain.
\end{abstract}

\section{INTRODUCTION}

Oncocytomas are tumours composed by oncocytes, cells with granular and eosinophilic cytoplasm filled with mitochondria. It is a neoplasm that can arise in several organs (more commonly described in the kidney, salivary gland and thyroid). Oncocytoma arising in the adrenal gland is a rare finding. Most of them are benign and non-functioning and are detected incidentally. However, functional adrenal oncocytomas presenting as Cushing's syndrome and pheochromocytoma have been reported.

\section{CASE REPORT}

55 years old woman with progressive weight gain in the last year.

Medical history: smoker, arterial hypertension, dyslipidemia, gastroesophageal reflux disease and past infection with the hepatitis $B$ virus. She had developed edema of her face, abdomen and ankles and had frequent headaches.

Physical examination: truncal and centripetal obesity, thin extremities with muscle atrophy, plethoric moon face, echymoses and hirsutism. Blood pressure: 120/85 treated with losartan $50 \mathrm{mg} / 24 \mathrm{~h}$, amiloride hydrochlorothiazide $5 / 50 \mathrm{mg} / 24 \mathrm{~h}$ and atenolol $50 \mathrm{mg} / 24 \mathrm{~h}$.

Laboratory evaluation: fasting blood glucose 86 $\mathrm{mg} / \mathrm{dl}$, total cholesterol $218 \mathrm{mg} / \mathrm{dl}, \mathrm{HbA}_{1 \mathrm{c}}$ $6.3 \%$, TSH $0.96 \mu \mathrm{lU} / \mathrm{ml}$, serum cortisol (8 a.m.) $22 \mu \mathrm{g} / \mathrm{dl}$ (5-25), serum cortisol (after $1 \mathrm{mg}$ overnight dexamethasone suppression) 10 $\mu \mathrm{g} / \mathrm{dl}$, serum cortisol (after $0.5 \mathrm{mg}$ dexamethasone every $6 h$ for $48 h$ suppression) $27 \mu \mathrm{g} / \mathrm{dl}$, urinary free cortisol repeatedly reased (593, $388 \mu \mathrm{g} / 24 \mathrm{~h})$, ACTH $1 \mathrm{pg} / \mathrm{dl}$, rest adrenal hormonal profile normal.

Computed tomography: $2.2 \mathrm{~cm}$ mass in the right adrenal gland. From these findings, the final diagnosis for this patient was Cushing's syndrome and we decided laparoscopic right adrenalectomy.

The patient is receiving glucocorticoid replacement therapy 6 months after the surgery with progressive reduction. She is waiting to see clinical and analytical evolution to suspend such treatment

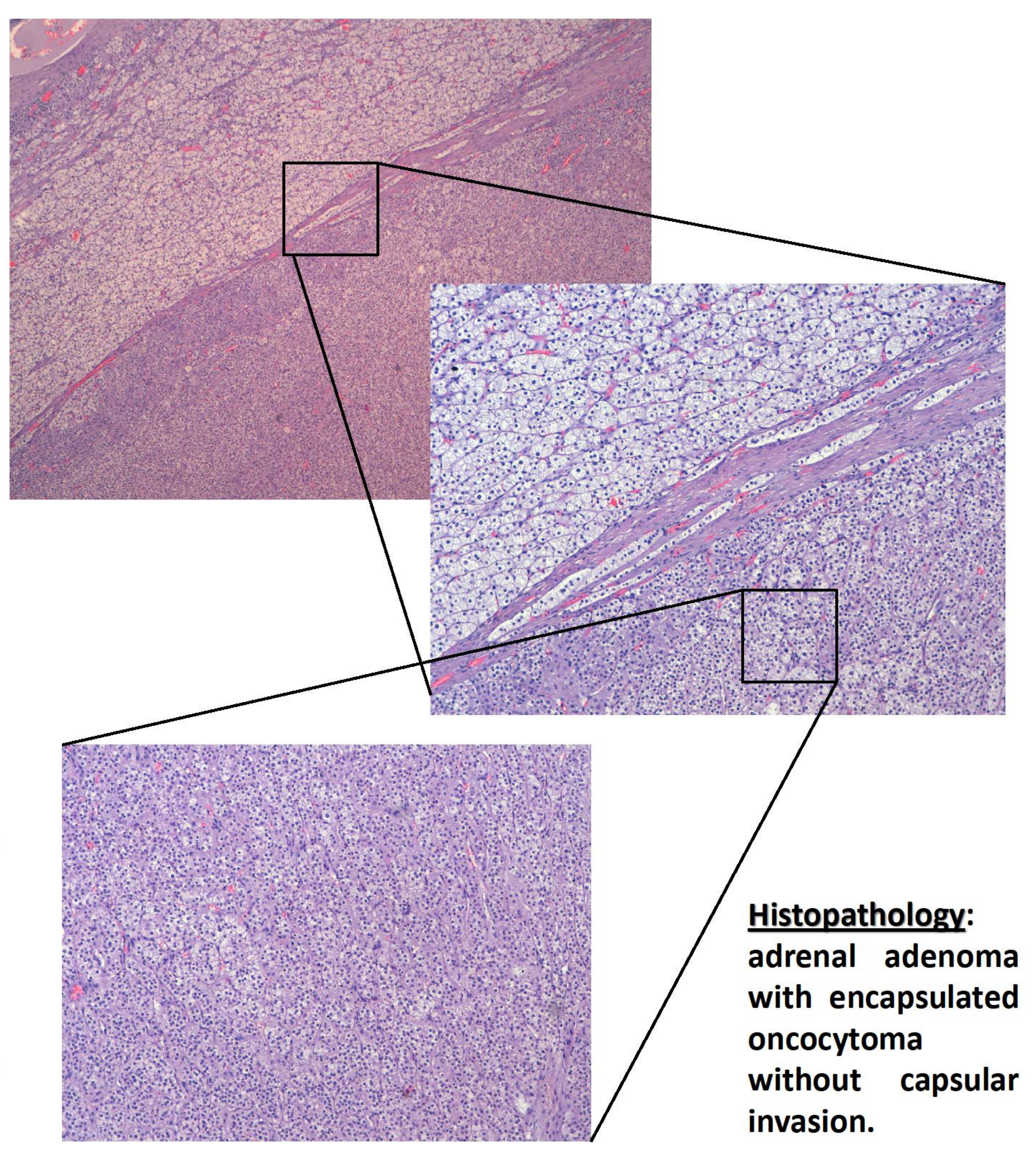

\section{CONCLUSION}

Adrenocortical oncocytoma, although extremely rare, should be considered in the differential diagnosis in adrenal masses. They are usually non-functional and benign but few cases are functioning tumours and may cause Cushing's syndrome. To make a correct diagnosis, biochemical, clinical and histological features must be analyzed together. 